ARTICLE

\title{
Surface passivated halide perovskite single-crystal for efficient photoelectrochemical synthesis of dimethoxydihydrofuran
}

\author{
Xu-Dong Wang ${ }^{1}$, Yu-Hua Huang ${ }^{1}$, Jin-Feng Liao ${ }^{1}$, Ze-Feng Wei ${ }^{1}$, Wen-Guang Li ${ }^{1}$, Yang-Fan Xu (1) ${ }^{1}$, \\ Hong-Yan Chen ${ }^{1} \&$ Dai-Bin Kuang (i) ${ }^{1 凶}$
}

Halide perovskite single-crystals have recently been widely highlighted to possess high light harvesting capability and superior charge transport behaviour, which further enable their attractive performance in photovoltaics. However, their application in photoelectrochemical cells has not yet been reported. Here, a methylammonium lead bromide $\mathrm{MAPbBr}_{3}$ singlecrystal thin film is reported as a photoanode with potential application in photoelectrochemical organic synthesis, 2,5-dimethoxy-2,5-dihydrofuran. Depositing an ultrathin $\mathrm{Al}_{2} \mathrm{O}_{3}$ layer is found to effectively passivate perovskite surface defects. Thus, the nearly 5 -fold increase in photoelectrochemical performance with the saturated current being increased from 1.2 to $5.5 \mathrm{~mA} \mathrm{~cm}^{-2}$ is mainly attributed to suppressed trap-assisted recombination for $\mathrm{MAPbBr}_{3}$ single-crystal thin film $/ \mathrm{Al}_{2} \mathrm{O}_{3}$. In addition, $\mathrm{Ti}^{3+}$-species-rich titanium deposition has been introduced not only as a protective film but also as a catalytic layer to further advance performance and stability. As an encouraging result, the photoelectrochemical performance and stability of $\mathrm{MAPbBr}$ single-crystal thin film/ $/ \mathrm{Al}_{2} \mathrm{O}_{3} / \mathrm{Ti}$-based photoanode have been significantly improved for $6 \mathrm{~h}$ continuous dimethoxydihydrofuran evolution test with a high Faraday efficiency of $93 \%$.

\footnotetext{
${ }^{1}$ MOE Key Laboratory of Bioinorganic and Synthetic Chemistry, Lehn Institute of Functional Materials, School of Chemistry, Sun Yat-sen University, Guangzhou, P. R. China. ${ }^{凶}$ email: kuangdb@mail.sysu.edu.cn
} 
$\mathrm{n}$ the past decade, the vast latent capacity of halide perovskites in solar energy utilization has been reported; e.g., perovskite solar cells showed a power conversion efficiency of $25.5 \%{ }^{1}$. In addition to solar-to-electricity conversion, the high light harvesting capability, superior carrier transport, and suitable band position of halide perovskites motivate the wide applications of these materials in photocatalysis and photoelectrochemical (PEC) fields ${ }^{2-6}$. Compared to particulate photocatalytic systems, PEC systems feature semiconductor photocatalysts and external biases and thereby exhibit significant advantages in high-efficiency charge separation and collection as well as easy catalyst recycling7. Recently, halide perovskite polycrystalline thin films (PCTFs) have been exploited for PEC water splitting and $\mathrm{CO}_{2}$ reduction $^{8-17}$. The use of organic solvent instead of water not only is expected to improve the stability of photoelectrode ${ }^{18}$, but also enables a broader set of organic synthesis reactions, achieving higher Faradaic efficiency and value-added chemicals ${ }^{19-25}$. Compared to PCTFs, perovskite single-crystal thin films (SCTFs) inherit the advantages of both polycrystalline films and bulk single crystals ${ }^{26}$, such as low trap-state densities, long carrier diffusion lengths, well-defined thicknesses and, more importantly, high stability, which thus has pinned great expectation as more promising photoelectrodes for PEC applications.

2,5-Dimethoxy-2,5-dihydrofuran (DMDF) has been considered a key intermediate for producing pyridines, pyridazines, pyrroles, benzenoid compounds, and coumarin analogs ${ }^{27-30}$. In its traditional chemical synthetic method, a large amount of bromine is employed as an oxidant, the mass usage of which raises issues of environmental pollution ${ }^{29}$. As an alternative approach to produce DMDF, electrochemical oxidation of furan can be mildly implemented in $\mathrm{NH}_{4} \mathrm{Br}$ alcoholic solution. In 2017, Sayama and co-worker provided another more direct approach based on a PEC system using $\mathrm{BiVO}_{4} / \mathrm{WO}_{3}$ as a photoanode with a $\mathrm{Br}^{+} / \mathrm{Br}^{-}$mediator under visible light irradiation ${ }^{30}$. PEC synthesis has been found to significantly lower the required applied potential; however, the resulting photocurrent density is slightly unsatisfactory $\left(<0.55 \mathrm{~mA} \mathrm{~cm}^{-2}\right)$. Currently, it is reasonable to expect that halide perovskite SCTFs could deliver advanced PEC performance towards DMDF production, considering their remarkable photoelectric properties. However, the utilization of perovskite-based PEC cells for organic synthesis remains unexplored.

Herein, methylammonium lead bromide $\mathrm{MAPbBr}_{3} \mathrm{SCTF}$ grown on a conductive FTO glass substrate is demonstrated as an efficient photoanode in a PEC cell to afford a high turnover rate for artificial photosynthesis of DMDF from furan. The surface is the most vulnerable to defects and passivation of single-crystal surface defects is the most important task. The subsequent deposition of $\mathrm{Al}_{2} \mathrm{O}_{3}$ and $\mathrm{Ti}$ overlayers significantly promoted the operating stability and photocatalytic activity of $\mathrm{MAPbBr}_{3}$ SCTFs. As an encouraging result, the highest photocurrent of $7.8 \mathrm{~mA} \mathrm{~cm}^{-2}(0.8 \mathrm{~V}$ vs. $\mathrm{Ag} / \mathrm{AgCl})$ is achieved for $\mathrm{MAPbBr}_{3}$ $\mathrm{SCTF} / \mathrm{Al}_{2} \mathrm{O}_{3} / \mathrm{Ti}$. Such work paves the way for the future design of high-performance perovskite SCTF-based solar-driven photosynthesis systems.

\section{Results and discussion}

PEC characterizations of $\mathrm{MAPbBr}_{3}$ SCTF and PCTF. MAPbBr SCTFs were grown in situ on an $\mathrm{FTO} / \mathrm{TiO}_{2}$ substrate through our previously reported space-limited crystallization method with some modifications ${ }^{31,32}$. The as-prepared $\mathrm{MAPbBr}_{3}$ SCTF exhibits a smooth and pinhole-free surface with a lateral size of $11.5 \mathrm{~mm} \times 7.6 \mathrm{~mm}$ and a film thickness of approximately $14 \mu \mathrm{m}$ (Fig. 1a, b and Supplementary Fig. 1a). In contrast, a 300-nmthick $\mathrm{MAPbBr}_{3}$ PCTF prepared by spin-coating (Fig. 1c and
Supplementary Fig. 1b) is composed of small crystals accompanied by abundant sharp grain boundaries (Fig. 1d). The configuration of the PEC cell system is depicted in Fig. 1e, where $\mathrm{MAPbBr}_{3}$ SCTF (or PCTF) on an $\mathrm{FTO} / \mathrm{TiO}_{2}$ substrate and a $\mathrm{Br}^{-} / \mathrm{Br}^{+}$redox couple in an acetonitrile/methanol mixed solution function as the photoanode and electrolyte, respectively. Ultraviolet photoelectron spectra (UPS, Supplementary Fig. 2a, b) show that the valence band maximum (VBM) of the $\mathrm{MAPbBr}_{3}$ SCTF is approximately $1.45 \mathrm{~V}$ vs. SHE, capable of bromine oxidation $(0.7 \mathrm{~V} \text { vs. SHE, Supplementary Fig. } 2 \mathrm{c})^{28}$. Upon light excitation, the $\mathrm{Br}^{-}$in the electrolyte will be oxidized into $\mathrm{Br}^{+}$ species by photogenerated holes, which then serve as oxidizing reagents to transform furan into DMDF. The resultant saturated photocurrent densities of $\mathrm{MAPbBr}_{3}$ PCTF and SCTF are 0.7 and $1.2 \mathrm{~mA} \mathrm{~cm}^{-2}$ at $0.20 \mathrm{~V}$ vs. $\mathrm{Ag} / \mathrm{AgCl}$ (Fig. 1f), respectively. Such a $70 \%$ enhancement in photocurrent density for $\mathrm{MAPbBr}_{3}$ SCTF is mainly ascribed to its high crystallinity, high charge mobility and low trap density ${ }^{31}$. In addition, it can be clearly seen that the photocurrent density of the $\mathrm{MAPbBr}_{3}$ PCTF PEC cell decreases rapidly within $\sim 3 \mathrm{~min}$, while that of the $\mathrm{MAPbBr}_{3}$ SCTF retains $54 \%$ of the initial value even after $30 \mathrm{~min}$ (Fig. $1 \mathrm{~g}$ ). This phenomenon is further supported by the stability of the materials in acetonitrile/methanol electrolyte (Supplementary Fig. 3). $\mathrm{MAPbBr}_{3} \mathrm{PCTF}$ decomposed within $25 \mathrm{~min}$, while $\mathrm{MAPbBr}_{3}$ SCTFs exhibit negligible degradation even after $20 \mathrm{~h}$, further demonstrating the better stability of SCTFs. The diffusion length of $\mathrm{MAPbBr}_{3}$ SCTF $(5.6 \mu \mathrm{m})^{31}$ is much higher than that of perovskite-based thin films $(0.33 \mu \mathrm{m})^{33}$. Electric fields can help carriers migrate from a $14 \mu \mathrm{m}$ thick single crystal to the surface and then participate in chemical reactions. On the premise of ensuring light absorption, further reducing the thickness of single crystal film is beneficial for shortening the carrier transmission distance and further improving the PEC performance. However, it is still challenging to control the perovskite single crystal films with large size and several microns thickness. In terms of influence of thickness on stability of perovskite film, thicker films tend to exhibit better stability (Supplementary Fig. 4). However, grain boundaries in PCTF have also been widely proven to primarily bear the brunt of perovskite degradation due to massively distributed trap states ${ }^{34}$. Therefore, the stability of the SCTF-based PEC cell can be mainly ascribed to the advantages of being few defect states.

Investigation of the $\mathrm{Al}_{2} \mathrm{O}_{3}$ passivation effect for $\mathrm{MAPbBr}_{3}$ SCTFs. Halide perovskite materials have been widely proven to have a low trap formation energy and reconfigurable surface lattice ${ }^{35,36}$, and therefore, surface trap states are easily formed as charge carrier recombination centers ${ }^{37}$. Herein, we deposit an ultrathin $\mathrm{Al}_{2} \mathrm{O}_{3}$ layer onto a $\mathrm{MAPbBr}_{3} \mathrm{SCTF}$ through atomic layer deposition (ALD) to further boost the PEC performance by reducing the amounts of surface trap states (see section "Experimental details" in the "Methods" section).

The presence of $\mathrm{Al}_{2} \mathrm{O}_{3}$ is first verified by the additional $\mathrm{Al} 2 p$ peak at $74.8 \mathrm{eV}$ in the X-ray photoelectron spectroscopy (XPS) spectra (Fig. 2a). Furthermore, characteristic signals of $\mathrm{Al}-\mathrm{CH}_{3}$, $(\mathrm{OH})-\mathrm{Al}=\mathrm{O}$ and $\mathrm{Al}-\mathrm{O}-\mathrm{Al}$ species are observed at 1256, 1080, and $888 \mathrm{~cm}^{-1}$ in the Fourier transform infrared (FTIR) spectra after ALD treatment, again proving the existence of $\mathrm{Al}_{2} \mathrm{O}_{3}$ (Supplementary Fig. 5a). During the process of ALD deposition of $\mathrm{Al}_{2} \mathrm{O}_{3}$, TMA reacts with $\mathrm{CH}_{3} \mathrm{NH}_{3}{ }^{+}$of $\mathrm{MAPbBr}_{3}$ and results in $\mathrm{CH}_{3} \mathrm{NH}_{2}$ release accompanied by the formation of $\mathrm{Br}_{3} \mathrm{~Pb}-\mathrm{Al}$ $\left(\mathrm{CH}_{3}\right)-\mathrm{PbBr}_{3}$ intermediates (Fig. 2d) ${ }^{38}$, which further react with $\mathrm{O}_{2}$ to produce $\mathrm{Al}_{2} \mathrm{O}_{3}$. Further insight into the chemical modification on the perovskite surface was provided by comparing the surface XPS spectra of $\mathrm{N} 1 s, \mathrm{~Pb} 4 f$, and $\mathrm{Br} 3 d$ before and 

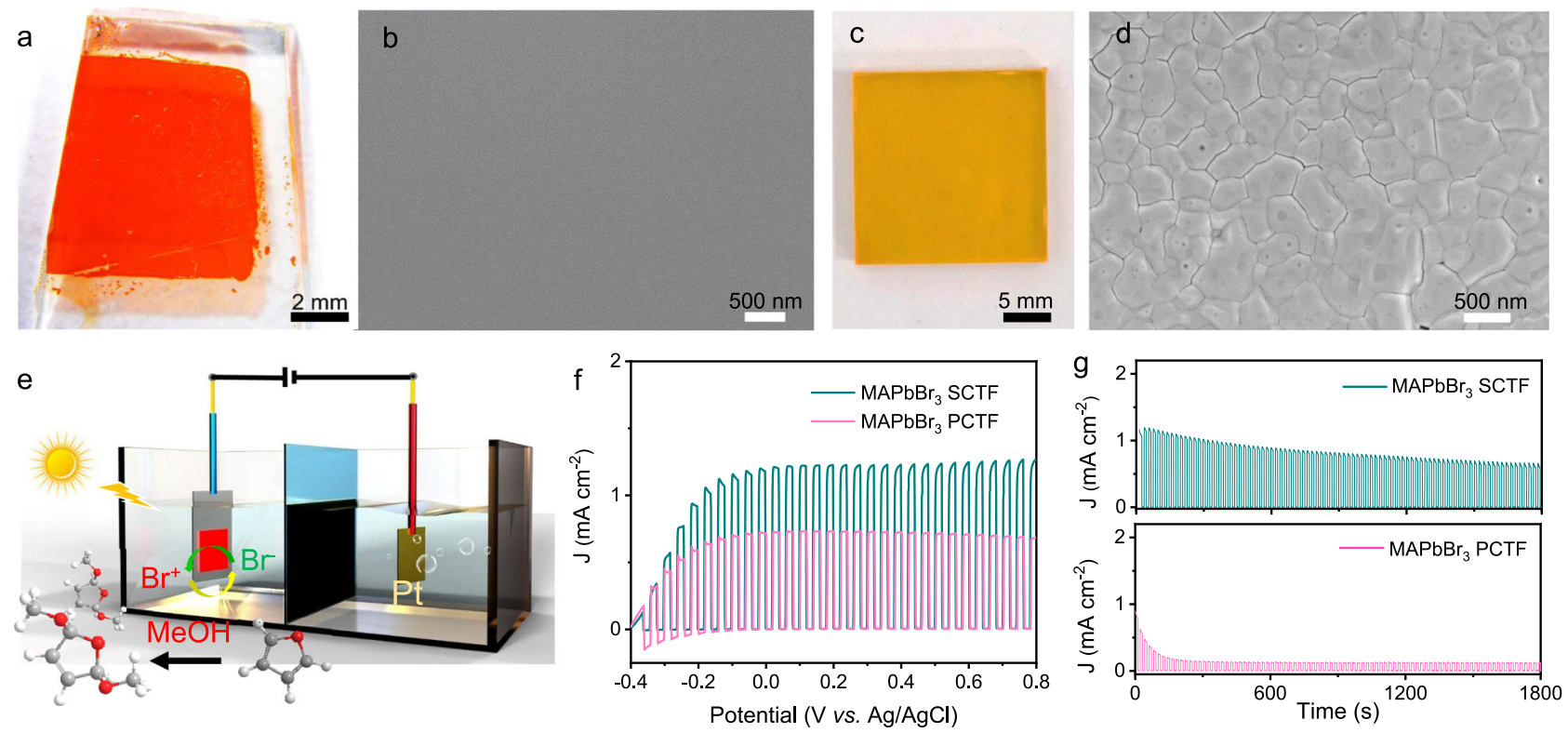

Fig. 1 Comparison of $\mathbf{M A P b B r}_{\mathbf{3}}$ SCTF with PCTF. Optical microscopy and SEM images of $\mathrm{MAPbBr}_{3} \mathrm{SCTF}(\mathbf{a}, \mathbf{b})$ and PCTF (c, d). e Schematic configuration of the proposed working principle of $\mathrm{MAPbBr}_{3}$ SCTF-based (or PCTF-based) PEC cells. $\mathbf{f}$ Linear sweep voltammetry (LSV) of MAPbBr 3 SCTF-based and PCTF-based photoelectrodes. $g$ Chronoamperometric trace of $\mathrm{MAPbBr}_{3} \mathrm{SCTF}$-based and PCTF-based photoelectrodes recorded at an applied potential of $0.2 \mathrm{~V}$ vs. $\mathrm{Ag} / \mathrm{AgCl}$.

after $\mathrm{Al}_{2} \mathrm{O}_{3}$ deposition (Fig. 2a-c). The intensity of the $\mathrm{N} 1 s$ peak is significantly weakened due to $\mathrm{CH}_{3} \mathrm{NH}_{2}$ release. Furthermore, both $\mathrm{Pb} 4 f_{7 / 2}$ and $\mathrm{Pb} 4 f_{5 / 2}$ peaks (Fig. 2c) shift to lower binding energy values by $0.37 \mathrm{eV}$ after the ALD process because of the $\mathrm{Pb}$ rich surface defects bonded with adsorbed oxygen ${ }^{39,40}$, which can additively suppress nonradiative recombination on the perovskite surface. The surface microstructure of the $\mathrm{MAPbBr}_{3}$ SCTF is well retained after $\mathrm{Al}_{2} \mathrm{O}_{3}$ deposition, as revealed from the scanning electron microscopy (SEM) image (Supplementary Fig. 5b). Identical X-ray diffraction (XRD) patterns are observed in $\mathrm{MAPbBr}_{3}$ SCTF and $\mathrm{MAPbBr}{ }_{3} \mathrm{SCTF} / \mathrm{Al}_{2} \mathrm{O}_{3}$ with the same growth orientation along the (h00) crystal plane, which not only reveals that the crystal phase of perovskite is well preserved during the ALD process, but also implies that the deposited $\mathrm{Al}_{2} \mathrm{O}_{3}$ is thin/amorphous (Supplementary Fig. 6).

A batch of $\mathrm{MAPbBr}_{3} \operatorname{SCTF} / \mathrm{Al}_{2} \mathrm{O}_{3}(0,1,5$, and $10 \mathrm{~nm})$ were fabricated by adjusting the ALD deposition cycles to unlock the effect of the $\mathrm{Al}_{2} \mathrm{O}_{3}$ layer on the PEC performance. $\mathrm{Al}_{2} \mathrm{O}_{3}$ thickness is achieved by controlling the number of ALD deposition cycles. Approximately $0.1 \mathrm{~nm}$ of aluminum oxide was deposited per cycle (for instance, 50 cycles, namely $5 \mathrm{~nm}$ ). As shown in Fig. 2e, the saturated photoanode current density of the pristine $\mathrm{MAPbBr}_{3} \mathrm{SC}$ film is $\sim 1.2 \mathrm{~mA} \mathrm{~cm}{ }^{-2}$ at $0.4 \mathrm{~V}$ vs. $\mathrm{Ag} / \mathrm{AgCl}$ $(0.53 \mathrm{~V}$ vs. SHE, Supplementary Fig. 7$)$, which gradually increases with thickening $\mathrm{Al}_{2} \mathrm{O}_{3}$ and reaches a maximum value of $5.5 \mathrm{~mA}$ $\mathrm{cm}^{-2}$ at $5 \mathrm{~nm}$ of $\mathrm{Al}_{2} \mathrm{O}_{3}$. The enhanced PEC performance affirms that the ultrathin $\mathrm{Al}_{2} \mathrm{O}_{3}$ layer would not hinder photogenerated holes injection from perovskite to the electrolyte due to charge tunnelling. Comparing with pristine $\mathrm{MAPbBr}_{3} \mathrm{SC}$, coating a thin $\mathrm{Al}_{2} \mathrm{O}_{3}$ overlayer with a thickness of $1-10 \mathrm{~nm}$ resulted in slight overpotential increasement. This is because that deposited $\mathrm{Al}_{2} \mathrm{O}_{3}$ can isolate the photoelectrode from the electrolyte, therefore the photocorrosion phenomenon of $\mathrm{MAPbBr}_{3} \mathrm{SC}$ being oxidized can be effectively suppressed. Meanwhile, with the increase of the thickness of $\mathrm{Al}_{2} \mathrm{O}_{3}$ overlayer, the passivation of effect of $\mathrm{MAPbBr}_{3}$ SC surface is more sufficient, so that the thicker $10 \mathrm{~nm} \mathrm{Al}_{2} \mathrm{O}_{3}$ can reduce the overpotential comparing to the thinner $\mathrm{Al}_{2} \mathrm{O}_{3}$ ( 1 and $5 \mathrm{~nm}$ ). The specific passivation mechanism will be discussed later.
However, further thickening of the $\mathrm{Al}_{2} \mathrm{O}_{3}$ layer (e.g., $10 \mathrm{~nm}$ ) attenuated the photoanodic current density, probably due to the aggrandized charge transport resistance as a result of its intrinsic insulating properties. The PEC performance of $\mathrm{MAPbBr}_{3} \mathrm{SCTF} /$ $\mathrm{Al}_{2} \mathrm{O}_{3}(5 \mathrm{~nm})$ is $\sim 10$ times higher than that of a previously reported $\mathrm{BiVO}_{4} / \mathrm{WO}_{3}$ photoanode with a maximum photocurrent of $0.55 \mathrm{~mA} \mathrm{~cm}^{-2}$ at $0.5 \mathrm{~V}$ vs. SHE $)^{28}$. We have also investigated the influence of $\mathrm{Al}_{2} \mathrm{O}_{3}$ thickness on the stability. The stability of the electrode gradually improved with the increase of the thickness of $\mathrm{Al}_{2} \mathrm{O}_{3}$ from 0 to $10 \mathrm{~nm}$ (Supplementary Fig. 8), since the deposited $\mathrm{Al}_{2} \mathrm{O}_{3}$ can isolate photoelectrode from the electrolyte.

To identify the underlying reason for the increased PEC performance after coupling with an ultrathin $\mathrm{Al}_{2} \mathrm{O}_{3}$ layer, the optical properties of $\mathrm{MAPbBr}{ }_{3} \mathrm{SCTF} / \mathrm{Al}_{2} \mathrm{O}_{3}$ were investigated. As shown in Fig. $2 \mathrm{f}$, the PL emission intensity of the $\mathrm{MAPbBr}_{3} \mathrm{SCTF}$ is significantly amplified after depositing 1-nm-thick $\mathrm{Al}_{2} \mathrm{O}_{3}$, and is further increased upon thickening of the $\mathrm{Al}_{2} \mathrm{O}_{3}$ layer to 5 and $10 \mathrm{~nm}$. Time-resolved PL (TRPL) decay plots at the emission maximum (Fig. 2g) also demonstrate that all $\mathrm{MAPbBr}_{3} \mathrm{SCTF} /$ $\mathrm{Al}_{2} \mathrm{O}_{3}$ samples decay sluggishly compared with pristine $\mathrm{MAPbBr}_{3}$ SCTF. Specifically, the fitted average PL decay time of $\mathrm{MAPbBr}_{3}$ SCTF $/ \mathrm{Al}_{2} \mathrm{O}_{3}(5 \mathrm{~nm})$ is twofold longer than that of pristine $\mathrm{MAPbBr}_{3}$ SCTF (Supplementary Table 1). This enhanced PL intensity and prolonged PL lifetime can be ascribed to the suppression of nonradiative recombination of electron-hole pairs in $\mathrm{MAPbBr}{ }_{3} \mathrm{SCTF} / \mathrm{Al}_{2} \mathrm{O}_{3}$. In addition, spatial and temporal imaging PL emission was monitored with a sample size of $100 \mu \mathrm{m} \times 100 \mu \mathrm{m}$. Figure 3a, c show confocal fluorescence images of pristine $\mathrm{MAPbBr}_{3}$ SCTF and $\mathrm{MAPbBr}{ }_{3} \mathrm{SCTF} / \mathrm{Al}_{2} \mathrm{O}_{3}(5 \mathrm{~nm})$. Apparently, greater brightness is observed for $\mathrm{MAPbBr}_{3} \mathrm{SCTF} /$ $\mathrm{Al}_{2} \mathrm{O}_{3}$, corresponding to stronger PL emission intensity. More importantly, brightness contrast appears with apparent darker spots in the images of pristine $\mathrm{MAPbBr}_{3}$ SCTF, but these spots are well dispelled after $\mathrm{Al}_{2} \mathrm{O}_{3}$ deposition, thus affording a uniform PL emission image (Fig. 3c). These darker spots on $\mathrm{MAPbBr}_{3}$ SCTF could be assigned to the region with higher surface trapstate density, and thus with active nonradiative charge carrier 

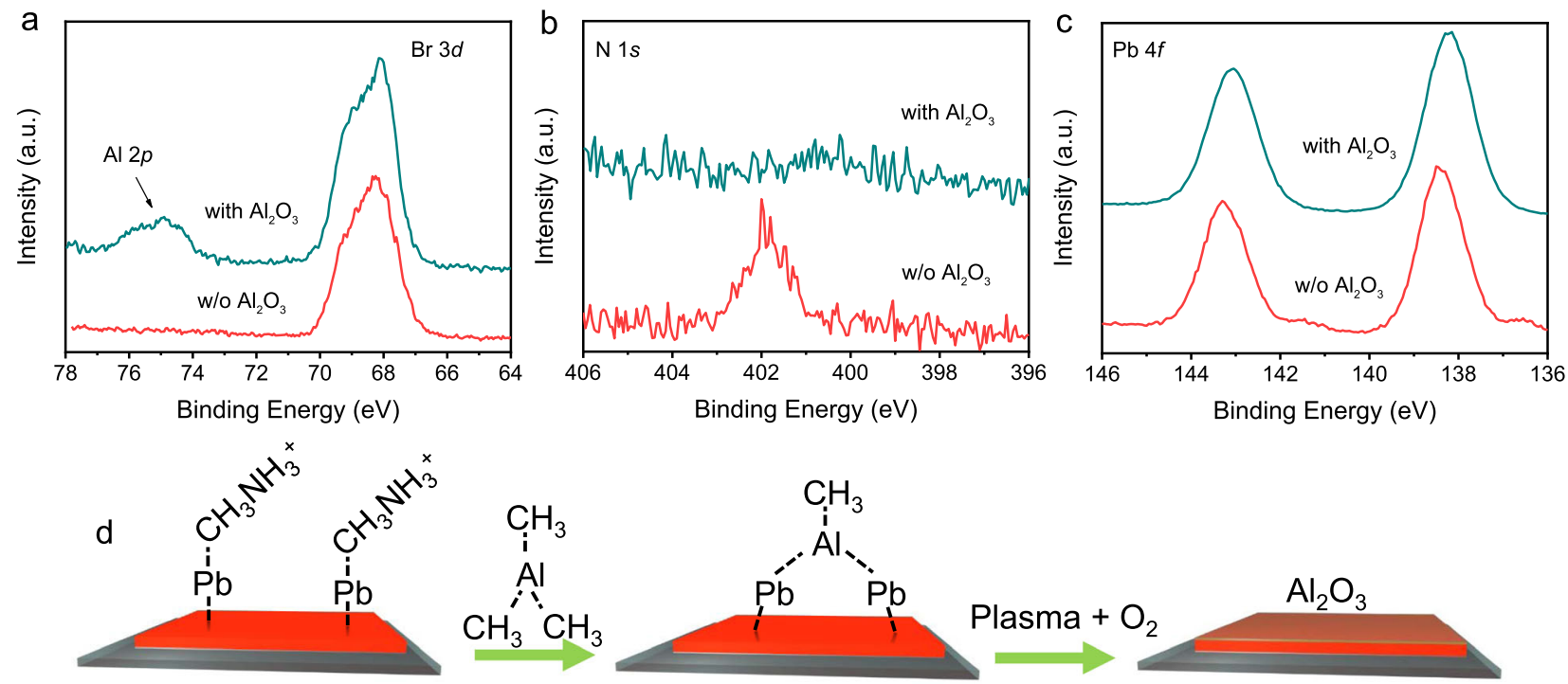

$-\mathrm{Br}_{3} \mathrm{~Pb}-\mathrm{CH}_{3} \mathrm{NH}_{3}{ }^{+}+\mathrm{Al}\left(\mathrm{CH}_{3}\right)_{3} \rightarrow \mathrm{Br}_{3} \mathrm{~Pb}-\mathrm{Al}\left(\mathrm{CH}_{3}\right)-\mathrm{PbBr}_{3}+\mathrm{CH}_{3} \mathrm{NH}_{2}+\mathrm{CH}_{4}$
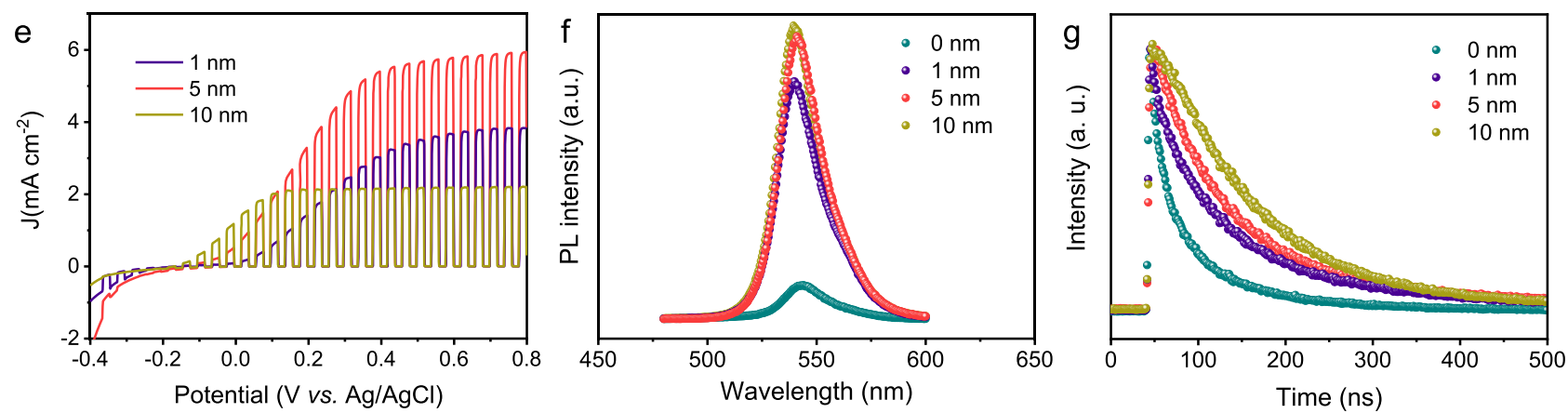

Fig. $2 \mathrm{Al}_{\mathbf{2}} \mathbf{O}_{\mathbf{3}}$ passivation effect investigation. XPS spectra of pristine $\mathrm{MAPbBr}_{3} \mathrm{SCTF}$ and $\mathrm{MAPbBr}_{3} \mathrm{SCTF} / \mathrm{Al}_{2} \mathrm{O}_{3}: \mathrm{Al} 2 \mathrm{p}$ and $\mathrm{Br} 3 d(\mathbf{a}), \mathrm{N} 1 \mathrm{~s}(\mathbf{b})$, and $\mathrm{Pb} 4 f$

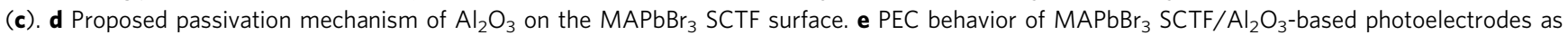
a function of $\mathrm{Al}_{2} \mathrm{O}_{3}$ deposition thickness. $\mathrm{Al}_{2} \mathrm{O}_{3}$-thickness-dependent steady-state photoluminescence ( $\mathrm{PL}$ ) spectra (f) and time-resolved $\mathrm{PL}$ decay curves $(\mathbf{g})$.

recombination ${ }^{41}$. Agreeing well with the TRPL test, fluorescence lifetime imaging microscopy (FLIM, Fig. 3b, d) data suggest a longer average PL lifetime for $\mathrm{MAPbBr}{ }_{3} \mathrm{SCTF} / \mathrm{Al}_{2} \mathrm{O}_{3}$ (553.5 ns) than for pristine $\mathrm{MAPbBr}_{3}$ SCTF (263.8 ns). These results strongly affirm the passivation role of $\mathrm{Al}_{2} \mathrm{O}_{3}$, which effectively suppresses the trap states on the perovskite surface ${ }^{42}$.

Different from the PL tests, transient reflection (TR) spectroscopy (Fig. 4a) can solely monitor the surface luminous and nonluminous species and provide detailed insight into the surface charge carrier dynamics, avoiding interferential signals from the bulk ${ }^{37,43}$. Both pristine $\mathrm{MAPbBr}_{3} \mathrm{SCTF}$ and $\mathrm{MAPbBr}_{3} \mathrm{SCTF} /$ $\mathrm{Al}_{2} \mathrm{O}_{3}$ feature a bandgap of $2.36 \mathrm{eV}$, corresponding to a UV-Vis absorption onset at $525 \mathrm{~nm}$ (Supplementary Fig. 9). Therefore, a $400 \mathrm{~nm}$ laser pulse with corresponding penetration depths of 80 $\mathrm{nm}$ was employed to excite only $\mathrm{MAPbBr}_{3}{ }^{44}$, and broadband continuum white light in the range of $450-700 \mathrm{~nm}$ was used as the probe pulse to monitor the reflection difference. Figure $4 \mathrm{~b}, \mathrm{c}$ show the pseudocolour TR spectra of pristine $\mathrm{MAPbBr}_{3}$ SCTF and $\mathrm{MAPbBr}{ }_{3} \mathrm{SCTF} / \mathrm{Al}_{2} \mathrm{O}_{3}$, both characterized by an intense signal at approximately $520 \mathrm{~nm}$. Accordingly, transient TR profiles recorded at a delay time of $5 \mathrm{ps}$ also show a typical antisymmetric peak centred at $520 \mathrm{~nm}$ (Fig. 4d, e). To clearly reveal the transient absorption (TA) difference upon light excitation, the inverse Hilbert transform (iHT) was performed according to the Kramers-Kronig relationship ${ }^{45}$. As displayed in
Fig. $4 \mathrm{~d}, \mathrm{e}$, the resultant TA curves after iHT exhibit a ground state bleaching peak centred at $\sim 520 \mathrm{~nm}$, agreeing well with the absorption onset. Due to the restricted time window ( $\leq 7 \mathrm{~ns})$ for the TR tests, the decay dynamics are mainly derived from the diffusion and recombination processes of surface photo-induced charge carriers ${ }^{46}$. The decay kinetics probed at $520 \mathrm{~nm}$ (Fig. 4f) were analysed and interpreted and show a very sluggish decay for $\mathrm{MAPbBr}_{3} \mathrm{SCTF} / \mathrm{Al}_{2} \mathrm{O}_{3}$ compared to that of the pristine $\mathrm{MAPbBr}_{3}$ SCTF (141 ps vs. $70 \mathrm{ps}$ ) due to the retardative surface trap-assisted recombination afforded by the ultrathin $\mathrm{Al}_{2} \mathrm{O}_{3}$ layer.

To further investigate the underlying effect of the $\mathrm{Al}_{2} \mathrm{O}_{3}$ layer on the electrical properties of the $\mathrm{MAPbBr}_{3}$ SCTF, Kelvin probe force microscopy (KPFM) was performed to probe the spatial charge transfer and separation on the perovskite. After subjection to the ALD $5 \mathrm{~nm}$ procedure, the $\mathrm{MAPbBr}_{3}$ SCTF surface appears slightly rougher with an increase in the root-mean-square value from 0.7 to $5.7 \mathrm{~nm}$ (Fig. 5a, d). Continuously distributed nanosized particles can be clearly observed in Fig. 5d, further corroborating that an ultrathin compact $\mathrm{Al}_{2} \mathrm{O}_{3}$ layer was uniformly deposited onto the $\mathrm{MAPbBr}_{3}$ SCTF, which is associated with island growth mechanism during ALD deposition of $\mathrm{Al}_{2} \mathrm{O}_{3}{ }^{38}$. The KPFM images and the corresponding line profiles of the surface photovoltage (SPV) difference are displayed in Fig. 5b, c, e, f. $\mathrm{MAPbBr}_{3}$ behaves as an $n$-type semiconductor according to UPS analysis, thus resulting in a space charge layer 
at the surface with an inherent electric field direction from the interior towards the surface ${ }^{47}$. The positive SPV values of $\mathrm{MAPbBr}_{3}$ SCTF and $\mathrm{MAPbBr}{ }_{3} \quad \mathrm{SCTF} / \mathrm{Al}_{2} \mathrm{O}_{3}$ indicated the photoinduced holes could transfer from the interior to surface of the sample. The SPV value of $\mathrm{MAPbBr}_{3} \mathrm{SCTF} / \mathrm{Al}_{2} \mathrm{O}_{3}$ is approximately $150 \mathrm{mV}$, twice higher than that of pristine $\mathrm{MAPbBr}_{3}$ PCTF $(75 \mathrm{mV})$, indicating richer density of holes accumulated onto the surface, which is beneficial for enhancing the PEC performance.
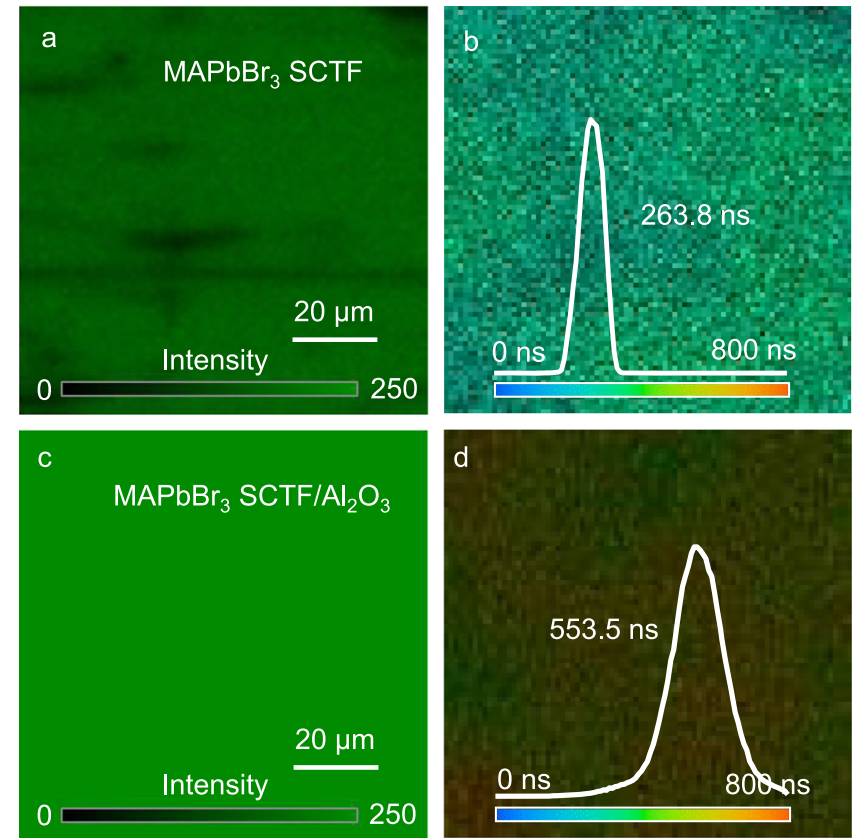

Fig. 3 Fluorescence spectroscopic measurements. Confocal fluorescence intensity images (left) and fluorescence lifetime imaging microscopy (FLIM) images (right) of pristine $\mathrm{MAPbBr}_{3} \mathrm{SCTF}(\mathbf{a}, \mathbf{b})$ and $\mathrm{MAPbBr}_{3} \mathrm{SCTF} /$ $\mathrm{Al}_{2} \mathrm{O}_{3}(\mathbf{c}, \mathbf{d})$.
Investigation of the Ti layer effect on the PEC performance of $\mathrm{MAPbBr}_{3}$ SCTFs. The above experimental results reveal that the $\mathrm{Al}_{2} \mathrm{O}_{3}$ passivation layer significantly enhances the PEC performance and the stability of the photoelectrode to some extent. However, due to its ultrathin thickness, long-term PEC stability is still challenging to maintain. Conductive overlayers have been widely proven to enhance the operating stability and even catalytic activity of semiconductor materials ${ }^{8,13}$. Thus, a $145-\mathrm{nm}$ thick Ti layer with a particle size of approximately $30 \mathrm{~nm}$ (Supplementary Fig. 10) was introduced onto $\mathrm{MAPbBr}{ }_{3} \mathrm{SCTF} / \mathrm{Al}_{2} \mathrm{O}_{3}$ as a protective layer to avert direct interaction with the electrolyte. The $\mathrm{MAPbBr}_{3} \mathrm{SCTF} / \mathrm{Al}_{2} \mathrm{O}_{3} / \mathrm{Ti}$ shows almost the same XRD pattern as $\mathrm{MAPbBr}_{3}$ (Supplementary Fig. 11a). The reasons beyond the failure to observe the characteristic XRD pattern of Ti layer probably can be concluded as follows: (a) the high crystallinity of perovskite single crystal leads to its diffraction signals completely overwhelms the Ti signals; (b) amorphous nature of the deposited Ti layer. In order to find out the underlying reasons, we have tried to deposit Ti layer on the surface of quartz. The XRD results (Supplementary Fig. 11b) show that there are two new phases, which can be assigned to the Ti (PDF\#01-074-7075) and rutile $\mathrm{TiO}_{2}$ (PDF\#04-008-7856) with low crystallinity. The formation of $\mathrm{TiO}_{2}$ is ascribed to the oxidation of titanium by residual oxygen in the system during the evaporation proces ${ }^{48}$. XPS spectrum (Supplementary Fig. 12) reveals that metallic $\mathrm{Ti}^{0+}$ (at 454.1 and $460.2 \mathrm{eV}$ ), $\mathrm{Ti}^{3+}$ (at 456.9 and $462.4 \mathrm{eV}$ ) and $\mathrm{Ti}^{4+}$ (at 458.7 and $464.4 \mathrm{eV}$ ) species are present, implying a $\mathrm{TiO}_{\mathrm{x}}$-rich surface ${ }^{49}$. Figure 6a displays the current-potential curves of the $\mathrm{MAPbBr}_{3} \mathrm{SCTF} / \mathrm{Al}_{2} \mathrm{O}_{3} /$ Ti-based PEC cell under chopped illumination. After incorporating the Ti layer on the $\mathrm{MAPbBr}_{3}$ SCTF $/ \mathrm{Al}_{2} \mathrm{O}_{3}$ photoanode, the onset potential $\left.(\sim 0.2 \mathrm{~mA} \mathrm{~cm})^{-2}\right)^{50}$ was negatively shifted by $120 \mathrm{mV}$. The photocurrent was saturated for $\mathrm{MAPbBr}_{3} / \mathrm{Al}_{2} \mathrm{O}_{3}(5 \mathrm{~nm})$ at $0.4 \mathrm{~V}$ vs. $\mathrm{Ag} / \mathrm{AgCl}$ with $5.5 \mathrm{~mA} \mathrm{~cm}^{-2}$. In contrast, the photocurrent is not saturated for $\mathrm{MAPbBr}{ }_{3} \mathrm{SCTF} / \mathrm{Al}_{2} \mathrm{O}_{3} / \mathrm{Ti}$ throughout all the test voltages from -0.4 to $0.8 \mathrm{~V}$, reaching $7.8 \mathrm{~mA} \mathrm{~cm}^{-2}$ at $0.8 \mathrm{~V}$ vs. $\mathrm{Ag} / \mathrm{AgCl}$. To confirm the catalytic activity of Ti layer, the electrochemical behavior of FTO/Ti and FTO was also studied (Supplementary
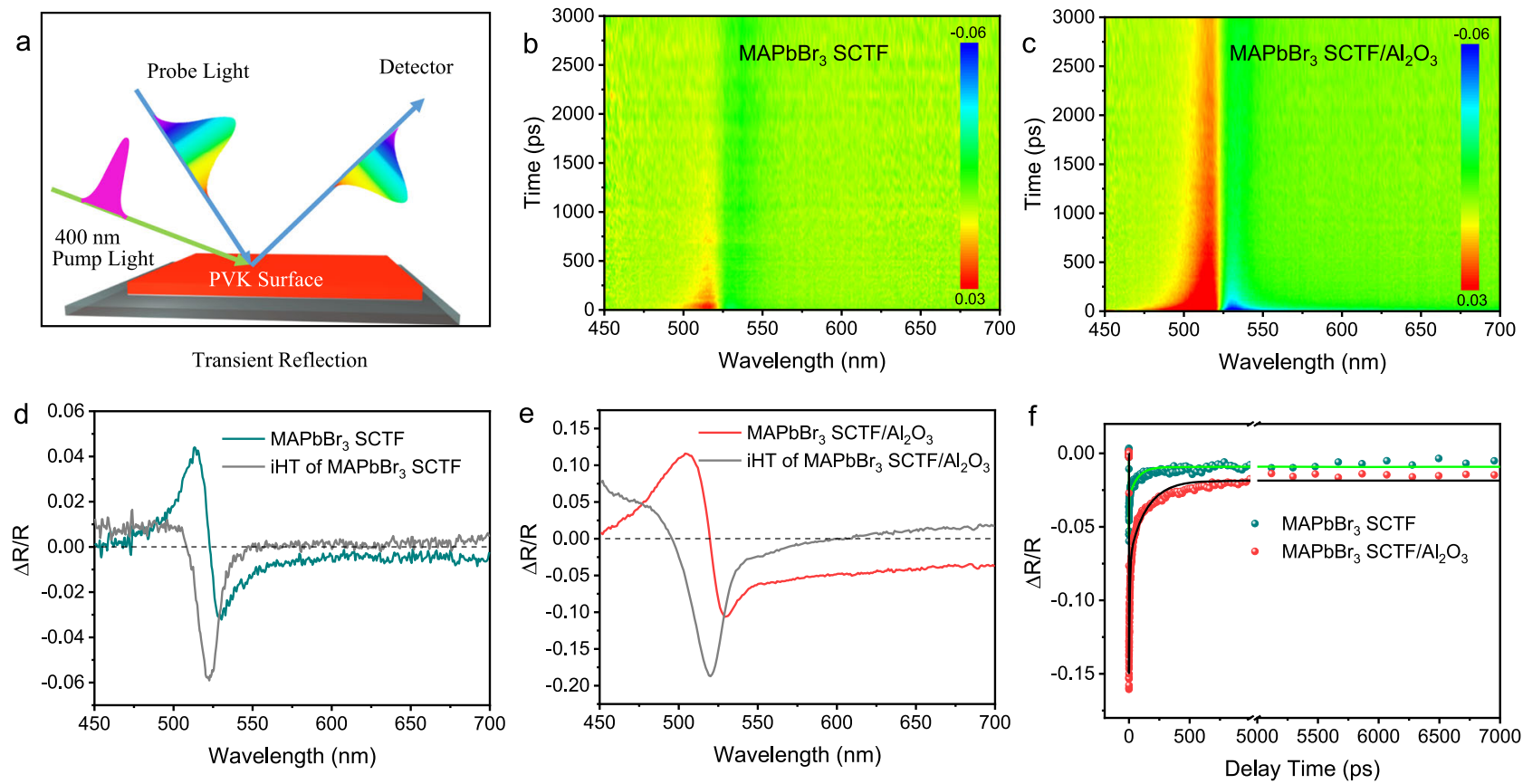

Fig. 4 Transient reflection spectroscopic measurements. a Diagram of transient reflection (TR); TR spectra pseudocolour images, and TR spectra recorded at a delay time of $5 \mathrm{ps}$ of pristine $\mathrm{MAPbBr}_{3} \mathrm{SCTF}(\mathbf{b}, \mathbf{d})$ and $\mathrm{MAPbBr}_{3} \mathrm{SCTF} / \mathrm{Al}_{2} \mathrm{O}_{3}(\mathbf{c}$, e). Kinetic fit of the data of these two SCTFs (f). 

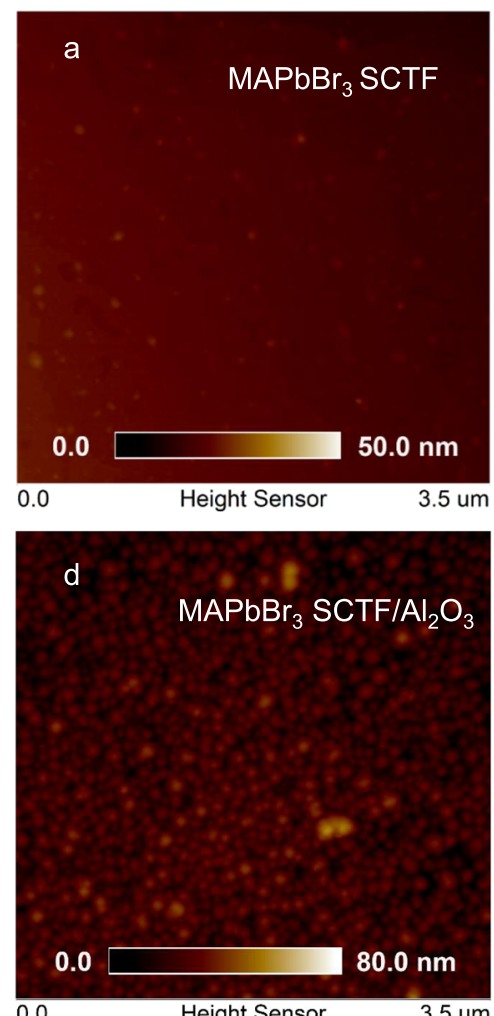

0.0

Height Sensor

3.5 um 0.0
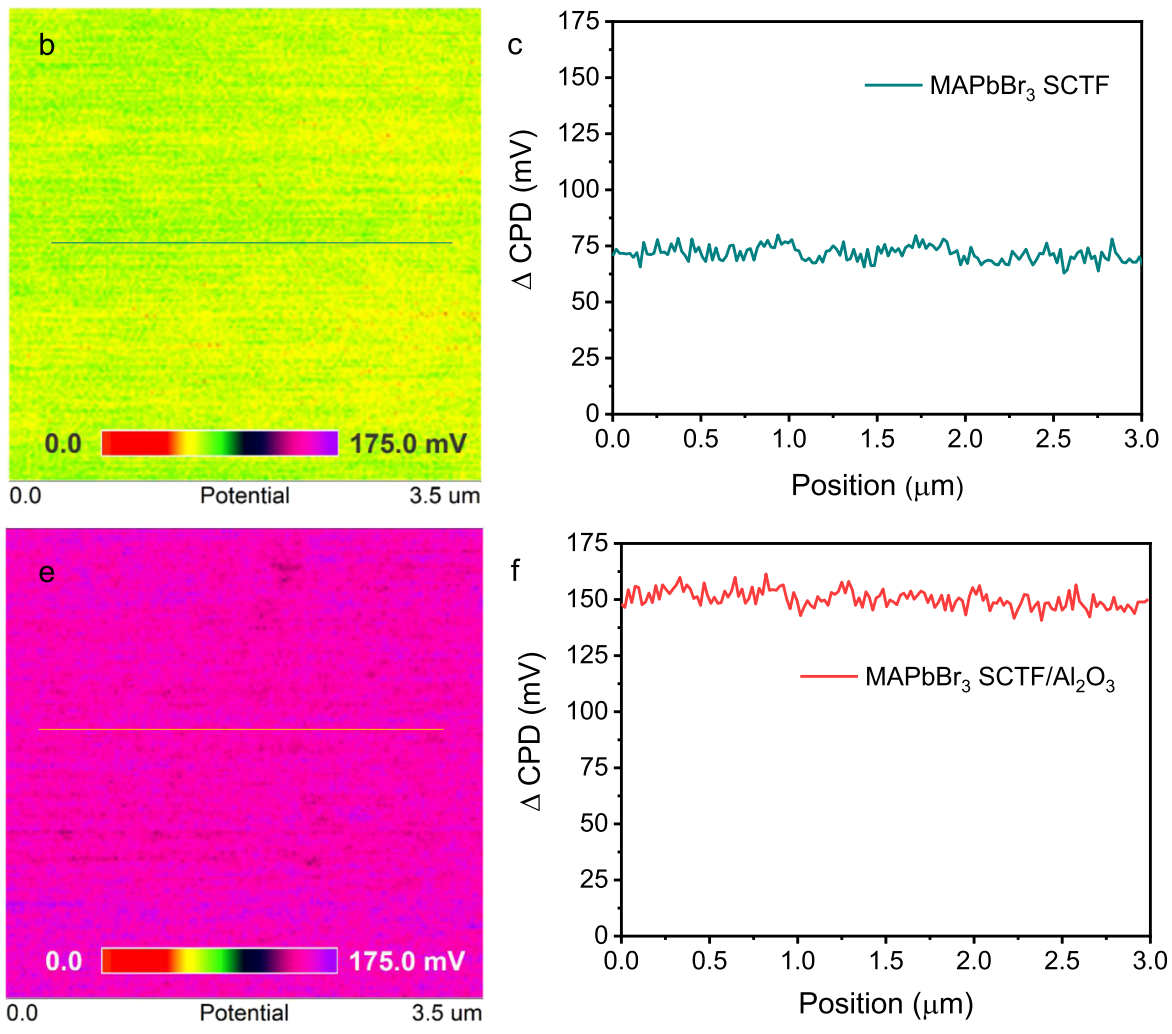

Fig. 5 Kelvin probe force microscopy. AFM topography images, KPFM images and $\triangle \mathrm{CPD}$ profiles (subtracting the potential in the dark from that under light irradiation) of pristine $\mathrm{MAPbBr}_{3} \mathrm{SC}$ film (a-c) and $\mathrm{MAPbBr}_{3} \mathrm{SCTF} / \mathrm{Al}_{2} \mathrm{O}_{3}$ (d-f).
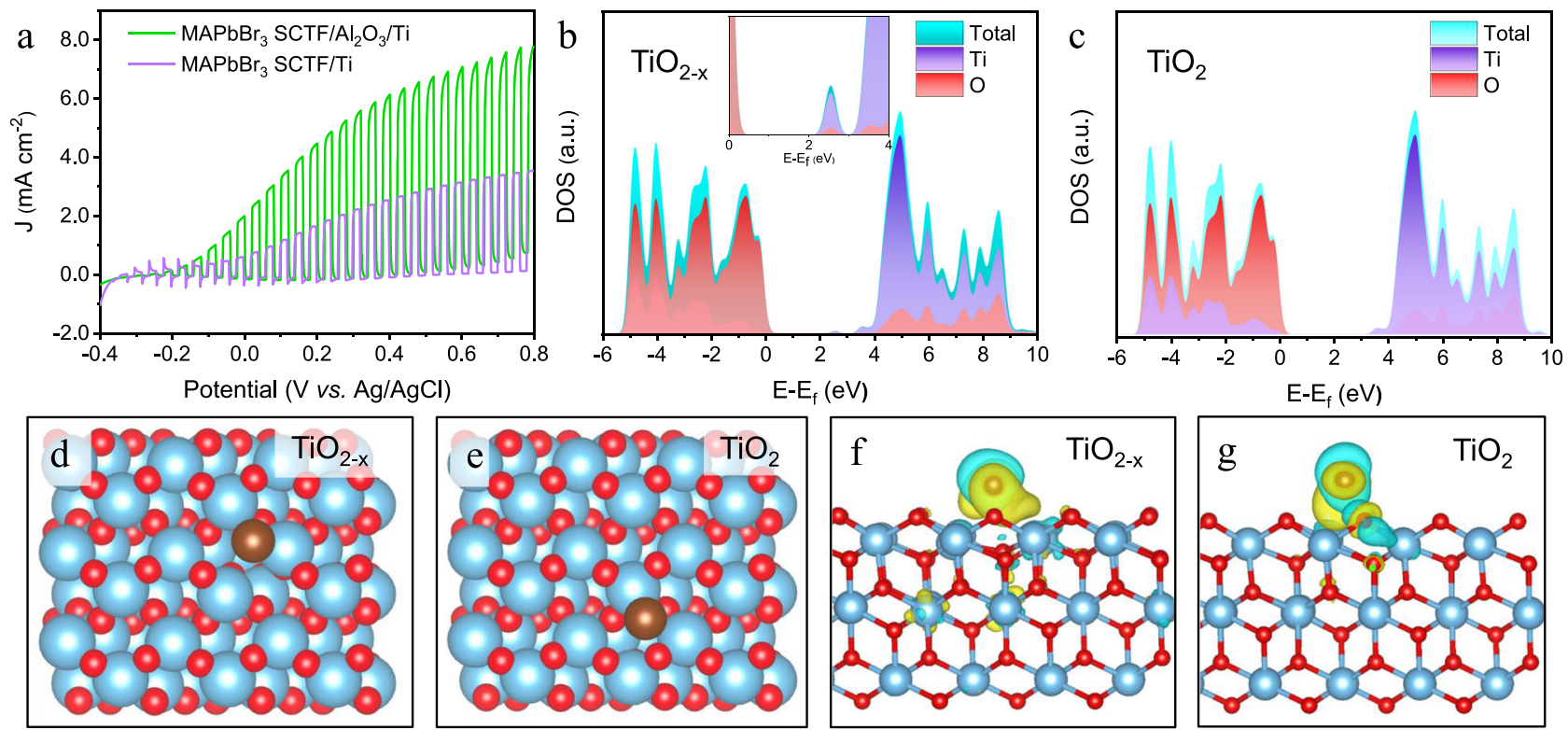

Fig. 6 Ti layer effect on the PEC performance. a PEC behaviors of $\mathrm{MAPbBr}_{3} \mathrm{SCTF} / \mathrm{Ti}$-based and $\mathrm{MAPbBr}_{3} \mathrm{SCTF} / \mathrm{Al} \mathrm{O}_{3} / \mathrm{Ti}^{-b a s e d}$ photoelectrodes. The projected DOS of $\mathbf{b} \mathrm{TiO}_{2-x}$ and $\mathbf{c} \mathrm{TiO}_{2}$. DFT-calculated adsorption of $\mathrm{Br}$ on the surfaces of $\mathbf{d} \mathrm{TiO}_{2-x}$ and $\mathbf{e} \mathrm{TiO}_{2}$. $\mathbf{f}$, $\mathbf{g} \mathrm{Corresponding}$ electron density difference, where yellow indicates a gain of electrons and cyan indicates loss of electrons.

Fig. 13). Compared with the weak anodizing current of the FTO electrode, the FTO/Ti electrode exhibited remarkable electrocatalytic activity towards bromine oxidation with a near-zero overpotential and an onset potential of $0.73 \mathrm{~V}$ vs. SHE $(0.60 \mathrm{~V}$ vs. $\mathrm{Ag} / \mathrm{AgCl}$ ). This result indicates that holes can easily be injected into the electrolyte and immediately participate in the chemical reaction due to the co-catalyst function of the Ti layer.
Density functional theory (DFT) calculations were conducted to shed light on the impact of $\mathrm{Ti}$ species on the electronic properties of the materials ${ }^{51}$. As shown in Supplementary Fig. 14, the calculated density of state (DOS) of Ti is continuous owing to its intrinsic metallic nature. Figure $6 \mathrm{~b}, \mathrm{c}$ illustrate that $\mathrm{Ti}^{3+}$ produces a higher density of oxygen vacancies and rearranges the band structure. The interaction between the $\mathrm{Br}$ atom and the 
three-atomic-layer $\mathrm{p}(3 \mathrm{x})$ surface was probed (Fig. 6d, e). The calculated $\mathrm{Br}$ adsorption energy is more negative for $\mathrm{TiO}_{2}$ $(-3.61 \mathrm{eV})$ than for $\mathrm{TiO}_{2-\mathrm{x}}(-0.57 \mathrm{eV})$, implying that $\mathrm{TiO}_{2-\mathrm{x}}$ has more potential as a $\mathrm{Br}$ oxidation catalyst. Upon adsorption, $\mathrm{Br}$ atoms suffer from charge redistribution and form chemical bonds with $\mathrm{Ti}$ atoms. The length of the $\mathrm{Ti}-\mathrm{Br}$ bond on the $\mathrm{TiO}_{2-\mathrm{x}}$ surface $(2.59 \AA)$ is estimated to be shorter than that on $\mathrm{TiO}_{2}$ $(2.67 \AA)$, agreeing well with its advantageous $\mathrm{Br}$ adsorption owing to the low-coordinated oxygen surface. The charge difference analysis in Fig. 6f, g displays a more significant charge transfer on the $\mathrm{TiO}_{2-\mathrm{x}}$ surface than on the $\mathrm{TiO}_{2}$ surface. Based on Mulliken charge analysis, the $\mathrm{Br}$ atom is $-0.26|\mathrm{e}|$ on $\mathrm{TiO}_{2-\mathrm{x}}$ but only $-0.06 \mid \mathrm{e}$ on $\mathrm{TiO}_{2}$. A similar trend has been observed based on Bader charge analysis, i.e., $-0.54|\mathrm{e}|$ on $\mathrm{TiO}_{2-\mathrm{x}}$ and $-0.26|\mathrm{e}|$ on $\mathrm{TiO}_{2}$. The increased electron cloud density of $\mathrm{Br}$ favours the harvesting of holes during the subsequent oxidation process. Similar phenomena have also been observed in defect-rich $\mathrm{TiO}_{2}$, where the oxygen vacancies and $\mathrm{Ti}^{3+}$ ions facilitate more efficient charge transfer ${ }^{52}$ and serve as an intrinsic active species to increase the electrochemical ${ }^{53}$, photocatalytic, and PEC activities $^{54}$. The current calculation results are consistent with the hypothesis that the introduction of catalytic active sites on the surface of the photoelectrode promotes the further improvement of PEC performance.

In addition to affording superior $\mathrm{PEC}$ performance, $\mathrm{Ti}$ overlayer can also protect the internal $\mathrm{Al}_{2} \mathrm{O}_{3}$ layer and perovskite layer. In order to further mitigate the influence of the electrolyte penetration from the edge, silicone sealant (Kafuter K-705) is used to encapsulate the edge of electrode. The resulted photoelectrode exhibited impressive stability for DMDF evolution, as displayed in Supplementary Fig. 15. The Br-mediated photogeneration of DMDF was carried out at $0.2 \mathrm{~V}$ vs. $\mathrm{Ag} / \mathrm{AgCl}$, which is lower than the potential required to initiate the electrochemical oxidation of bromine. The photocurrent density is well maintained even after $6 \mathrm{~h}$ of continual electrolysis at $0.2 \mathrm{~V}$. The formation of DMDF is confirmed via mass spectrometry (Supplementary Fig. 16), and the Faraday efficiency is calculated to be as high as $93 \%$, further promising its infinite potential as an effective and stable photoelectrode.

In summary, a MAPbBr 3 SCTF-based photoanode could drive the conversion of furan to DMDF has been demonstrated. Combined investigations with FLIM and TR as well as KPFM characterizations demonstrated that an ultrathin $\mathrm{Al}_{2} \mathrm{O}_{3}$ layer effectively suppressed trap-assisted nonradiative charge recombination, resulting in a doubled surface charge carrier lifetime. Furthermore, the subsequent deposited $\mathrm{Ti}$ layer not only stabilized the $\mathrm{MAPbBr}_{3} \mathrm{SCTF}$ by isolating perovskite from the electrolyte but also facilitated the bromine-mediated oxidation of furan owing to the $\mathrm{Ti}^{3+}$ catalytic active site. As a result, the highest photocurrent of $7.8 \mathrm{~mA} \mathrm{~cm}^{-2}$ at $0.8 \mathrm{~V}$ vs. $\mathrm{Ag} / \mathrm{AgCl}$ was realized for the $\mathrm{MAPbBr}_{3} \mathrm{SCTF} / \mathrm{Al}_{2} \mathrm{O}_{3} / \mathrm{Ti}$ photoanode. The photoanode retained remarkable stability for more than $6 \mathrm{~h}$ under chopped light illumination. Considering the lead-relatedtoxic issues 55,56 , stable lead-free perovskite SCTFs should deserve more future research focus towards environment-friendly and efficient photocatalysts, whose application will be potentially expanded to currently still challenging biomass conversion and organic synthesis reactions in the near future.

\footnotetext{
Methods

Synthesis of methylammonium bromide (MABr). A mixture of methylamine solution (30-33 wt\% in methanol, Aladdin) and hydrobromic acid (48 wt\% in water, Aladdin) with a molar ratio of 1:1.5 was stirred in an ice-water bath for $2 \mathrm{~h}$. After that, $\mathrm{MABr}$ powder was precipitated by rotary evaporating the solvent at $50{ }^{\circ} \mathrm{C}$ and then purified by recrystallization. The collected $\mathrm{MABr}$ powder was dried in a vacuum oven for $24 \mathrm{~h}$.
}

Fabrication of $\mathrm{MAPbBr}_{3}$ single-crystal thin films (SCTFs). $\mathrm{MAPbBr}_{3}$ SCTFs were grown onto $\mathrm{TiO}_{2}$-coated FTO glass substrates according to our previously reported method $^{31,32}$. First, FTO glass substrates $\left(7 \Omega\right.$ square $^{-1}$, Nipponsheet Glass) were sequentially cleaned by ultrasonication in detergent water, alcohol, and acetone for 30 min per step. A compact $\mathrm{TiO}_{2}$ layer was subsequently deposited on the cleaned FTO glass via spin-coating of a $\mathrm{TiO}_{2}$ colloidal solution at $4 \mathrm{k} \mathrm{rpm}$ for $30 \mathrm{~s}$, followed by an annealing process at $500{ }^{\circ} \mathrm{C}$ for $30 \mathrm{~min}$. The annealed $\mathrm{TiO}_{2}$ coated FTO substrate was further immersed into a $0.04 \mathrm{M} \mathrm{TiCl}_{4}$ solution at $70{ }^{\circ} \mathrm{C}$ for $30 \mathrm{~min}$ before a secondary annealing process at $500{ }^{\circ} \mathrm{C}$.

A space-limited model was assembled by sandwiching a thin polytetrafluoroethylene rectangular ring frame ( $20 \mu \mathrm{m}$ in thickness) into two pieces of $\mathrm{TiO}_{2}$-coated FTO glasses. Then, the $\mathrm{MAPbBr}$ precursor solution, prepared by dissolving equimolar $\mathrm{PbBr}_{2}$ and $\mathrm{MABr}$ in DMF, was circulated into the limited space between the two substrates by a peristaltic pump (BT100-2J, Longer Pump). Note that the bottom FTO glass was drilled with two holes to facilitate the circulation of the perovskite precursor solution. The middle part of the model was locally heated to $95{ }^{\circ} \mathrm{C}$ for crystallization and then maintained at $80^{\circ} \mathrm{C}$ for crystal growth. After $\sim 72 \mathrm{~h}$, the two FTO glasses were separated, with $\mathrm{MAPbBr}_{3}$ SCTFs grown in situ on the conductive substrate. The precipitated polycrystals were removed by $\gamma$-butyrolactone, and the residual solution was cleaned and removed by vacuum drying.

Fabrication of $\mathbf{M A P b B r}_{\mathbf{3}} \mathbf{P C T F}$. Equimolar $\mathrm{MABr}$ and $\mathrm{PbBr}_{2}$ were dissolved in DMF/DMSO $(3: 1, \mathrm{v}-\mathrm{v})$ at a concentration of $1.2 \mathrm{M}$. An appropriate amount of perovskite precursor solution was spin-coated onto the substrate with a ramp rate of $3000 \mathrm{rpm}$, and $200 \mu \mathrm{L}$ of chlorobenzene was dropped onto the spinning substrate $10 \mathrm{~s}$ after the spin-coating began. The obtained film was annealed at $120^{\circ} \mathrm{C}$ for $10 \mathrm{~min}$

Fabrication of $\mathrm{MAPbBr}_{3} \mathrm{SCTF} / \mathrm{Al}_{2} \mathrm{O}_{3} / \mathrm{Ti}$. An ultrathin aluminum oxide layer was grown on the surface of $\mathrm{MAPbBr}_{3} \mathrm{SCTF}$ by an atomic layer deposition (ALD) machine (ALD-SC6-PE, Syskey) with TMA and plasma oxygen as the element sources. In each ALD cycle, TMA was dosed into the chamber for $80 \mathrm{~ms}$ and purged out by Ar gas for $8 \mathrm{~s}$, followed by dosing plasma $\mathrm{O}_{2}$ into the chamber for $3 \mathrm{~s}$ and purging out by Ar gas for $8 \mathrm{~s}$. Approximately $0.1 \mathrm{~nm}$ of aluminum oxide was deposited per cycle. The ALD chamber was kept at a substrate temperature of $80^{\circ} \mathrm{C}$ to achieve effective deposition of $\mathrm{Al}_{2} \mathrm{O}_{3}$. Another thin layer of Ti was further deposited on the aluminum oxide layer by the thermal evaporation deposition method (SKY Technology Development).

Characterizations. XRD patterns were collected on a Rigaku Miniflex 600 X-ray diffractometer with $\mathrm{Cu} \mathrm{K}_{\alpha}$ radiation $(\lambda=1.5418 \AA)$. X-ray photoelectron spectroscopy (XPS) was performed by means of a Thermo-VG Scientific ESCALAB 250 Xray photoelectron spectrometer. The cross-sectional surface morphology and film thickness were examined by high-resolution field emission scanning electron microscopy (FE-SEM, Gemini 500). Atomic force microscopy (AFM) and scanning KPFM measurements were performed on a Bruker Dimension Fast Scan AFM system. UV-Vis absorption was obtained on an ultraviolet-visible spectrophotometer (Shimadzu UV-3600). Photoluminescence (PL) spectra were obtained on a fluorescence spectrophotometer (Edinburgh FLS980) with an excitation wavelength of $406 \mathrm{~nm}$. Confocal fluorescence images and fluorescence-lifetime imaging microscopy (FLIM) images were recorded on a Zeiss LSM880 NLO microscope with an excitation wavelength at $405 \mathrm{~nm}$. Transient reflectance spectra were measured on a Helios (Ultrafast Systems LLC) pump-probe setup in reflection mode. The pump beam at $400 \mathrm{~nm}$ was generated in a collinear optical parametric amplifier (OPerA Solo, Coherent) pumped by $800 \mathrm{~nm}$ fundamental pulses (100 fs, $1 \mathrm{kHz}$ repetition rate, Astrella-Tunable-V-F-1k, Coherent). A sapphire crystal was used to generate a broad white light continuum probe spectrum. The TR signal changes were recorded in the visible region from 450 to $700 \mathrm{~nm}$.

DFT calculations. DFT calculations were carried out by means of the $\mathrm{CP} 2 \mathrm{~K}$ package $^{57}$. The PBE functional ${ }^{58}$ with Grimme D3 correction ${ }^{59}$ and GoedeckerTeter-Hutter (GTH) pseudopotentials ${ }^{60,61}$ and DZVPMOLOPT-GTH basis sets ${ }^{62}$ were utilized to describe the system and the molecules, respectively. Unrestricted Kohn-Sham DFT was performed as the electronic structure method in the framework of the Gaussian and plane waves method ${ }^{62,63}$. A plane-wave energy cut-off of 500 Ry was employed. The adsorption energy $\left(E_{\mathrm{b}}\right)$ is defined as:

$$
E_{\mathrm{b}}=E_{\mathrm{Br} / \mathrm{sur}}-1 / 2 E_{\mathrm{Br}_{2}}(g)-E_{\text {sur }},
$$

where $E_{\mathrm{Br} / \text { sur }}, E_{\mathrm{Br}_{2}}$, and $E_{\text {sur }}$ are the surface $\mathrm{Br}$ adsorption energy and the individual electron density of the molecule and surface, respectively. The charge density difference $(\Delta \rho)$ is defined as

$$
\Delta \rho=\rho_{\mathrm{Br} / \mathrm{sur}}-\rho_{\mathrm{Br}}-\rho_{\mathrm{sur}}
$$

where $\rho_{\mathrm{Br} / \mathrm{sur}}, \rho_{\mathrm{Br}}$, and $\rho_{\text {sur }}$ are the electron density of surface-adsorbed $\mathrm{Br}$ and the individual electron density of $\mathrm{Br}$ and surface, respectively. 
Photoelectrochemical (PEC) measurements. PEC performance was measured on an electrochemical workstation (CHI660E, $\mathrm{CH}$ Instruments) at room temperature. A conventional three-electrode system with a Pt mesh as a counter electrode and $\mathrm{Ag} /$ $\mathrm{AgCl}_{(\text {sat } \mathrm{KCl})}$ as a reference electrode was adopted. To prevent dissolution and decomposition of perovskite, excessive $\mathrm{MABr}(2.02 \mathrm{~g})$ was added to a mixed solution of anhydrous acetonitrile $(45 \mathrm{~mL})$ and anhydrous methanol $(5 \mathrm{~mL})$ as an anolyte. To prepare the target product of 2,5-dihydro-2,5-dimethoxyfuran, an additional $2.5 \mathrm{~mL}$ of furan (Innochem) was added. For the catholyte, 1-butyl-1-methylpyrrolidinium bis(trifluoromethylsulfonyl)imide ( $3.47 \mathrm{~g}, 99 \%$, Shanghai Cheng Jie Chemical) and deionized water $(0.5 \mathrm{~mL})$ were added to anhydrous acetonitrile $(50 \mathrm{~mL})$. The linear sweep voltammogram (LSV) curves were measured at a scanning rate of $10 \mathrm{mV} \mathrm{s}^{-1}$ from $-0.4 \mathrm{~V}$ to $0.8 \mathrm{~V}$ vs. $\mathrm{Ag} / \mathrm{AgCl}$ under simulated solar illumination (Zolix, Gloria$\mathrm{X} 150 \mathrm{~A}, 100 \mathrm{~mW} \mathrm{~cm}^{-2}$, AM 1.5G filtered, calibrated with a standard Si solar cell). The light on/off was regulated by the light chopping equipment (Perfect Light, PFS40A). After the photoelectrocatalysis test, $2 \mathrm{~mL} \mathrm{H}_{2} \mathrm{O}$ was added into $1 \mathrm{~mL}$ of anode electrolyte and the solution was extracted with $0.5 \mathrm{~mL}$ ethyl acetate. The 2,5dihydro-2,5-dimethoxyfuran in the top organic layer was quantitatively analyzed by gas chromatography using commercial 2,5-dihydro-2,5-dimethoxyfuran (TCI Shanghai) diluted with ethyl acetate as an external standard.

\section{Data availability}

The data that support the plots within this paper are available from the corresponding author upon request.

Received: 23 September 2020; Accepted: 7 January 2021; Published online: 22 February 2021

\section{References}

1. National Renewable Energy Laboratory. Best research-cell efficiencies. https:// www.nrel.gov/pv/assets/pdfs/best-research-cell-efficiencies.20200925.pdf.

2. Park, S. et al. Photocatalytic hydrogen generation from hydriodic acid using methylammonium lead iodide in dynamic equilibrium with aqueous solution. Nat. Energy 2, 16185 (2016).

3. $\mathrm{Xu}, \mathrm{Y} .-\mathrm{F}$. et al. A CsPbBr 3 perovskite quantum dot/graphene oxide composite for photocatalytic $\mathrm{CO}_{2}$ reduction. J. Am. Chem. Soc. 139, 5660-5663 (2017).

4. $\mathrm{Da}, \mathrm{P}$. et al. High-performance perovskite photoanode enabled by $\mathrm{Ni}$ passivation and catalysis. Nano Lett. 15, 3452-3457 (2015).

5. Singh, S. et al. Hybrid organic-inorganic materials and composites for photoelectrochemical water splitting. ACS Energy Lett. 5, 1487-1497 (2020).

6. Wang, X. D. et al. In situ construction of a $\mathrm{Cs}_{2} \mathrm{SnI}_{6}$ perovskite nanocrystal/ $\mathrm{SnS}_{2}$ nanosheet heterojunction with boosted interfacial charge transfer. J. Am. Chem. Soc. 141, 13434-13441 (2019).

7. Zhang, L. et al. Photoelectrocatalytic arene C-H amination. Nat. Catal. 2 266-373 (2019).

8. Kim, I. S., Pellin, M. J. \& Martinson, A. B. F. Acid-compatible halide perovskite photocathodes utilizing atomic layer deposited $\mathrm{TiO}_{2}$ for solardriven hydrogen evolution. ACS Energy Lett. 4, 293-298 (2019).

9. Zhang, H. F. et al. A Sandwich-Like organolead halide perovskite photocathode for efficient and durable photoelectrochemical hydrogen evolution in water. Adv. Energy Mater. 8, 1800795 (2018).

10. Gao, L. F., Luo, W. J., Yao, Y. F. \& Zou, Z. G. An all-inorganic lead halide perovskite-based photocathode for stable water reduction. Chem. Commun. 54, 11459-11462 (2018).

11. Crespo-Quesada, M. et al. Metal-encapsulated organolead halide perovskite photocathode for solar-driven hydrogen evolution in water. Nat. Commun. 7, 12555 (2016).

12. Poli, I. et al. Graphite-protected $\mathrm{CsPbBr}_{3}$ perovskite photoanodes functionalised with water oxidation catalyst for oxygen evolution in water. Nat. Commun. 10, 2097 (2019).

13. Luo, J. S. et al. Water photolysis at $12.3 \%$ efficiency via perovskite photovoltaics and Earth-abundant catalysts. Science 345, 1593-1596 (2014)

14. Chen, J. et al. Compositionally screened eutectic catalytic coatings on halide perovskite photocathodes for photoassisted selective $\mathrm{CO}_{2}$ reduction. ACS Energy Lett. 4, 1279-1286 (2019).

15. Andrei, V. et al. Scalable triple cation mixed halide perovskite- $\mathrm{BiVO}_{4}$ tandems for bias-free water splitting. Adv. Energy Mater. 8, 1801403 (2018).

16. Andrei, V., Reuillard, B. \& Reisner, E. Bias-free solar syngas production by integrating a molecular cobalt catalyst with perovskite- $\mathrm{BiVO}_{4}$ tandems. Nat Mater. 19, 189-194 (2019).

17. Ahmad, S. et al. Triple-cation-based perovskite photocathodes with AZO protective layer for hydrogen production applications. ACS Appl Mater. Interfaces 11, 23198-23206 (2019).

18. $\mathrm{Li}, \mathrm{T}$. et al. Photoelectrochemical oxidation of organic substrates in organic media. Nat. Commun. 8, 390 (2017).
19. Hardwick, T., Qurashi, A., Shirinfar, B. \& Ahmed, N. Interfacial photoelectrochemical catalysis: solar-induced green synthesis of organic molecules. ChemSusChem 13, 1967-1973 (2020).

20. Barham, J. P. \& König, B. Synthetic Photoelectrochemistry. Angew. Chem. Int Ed. Engl. 59, 11732-11747 (2020)

21. Yu, Y., Guo, P., Zhong, J.-S., Yuan, Y. \& Ye, K.-Y. Merging photochemistry with electrochemistry in organic synthesis. Org. Chem. Front. 7, 131-135 (2020).

22. Han, C. et al. Recent progress in engineering metal halide perovskites for efficient visible-light-driven photocatalysis. ChemSusChem 13, 4005-4025 (2020).

23. Zhu, X., Lin, Y., Sun, Y., Beard, M. C. \& Yan, Y. Lead-halide perovskites for photocatalytic alpha-alkylation of aldehydes. J. Am. Chem. Soc. 141, 733-738 (2019).

24. Dai, Y., Poidevin, C., Ochoa-Hernandez, C., Auer, A. A. \& Tuysuz, H. A supported bismuth halide perovskite photocatalyst for selective aliphatic and aromatic C-H bond activation. Angew. Chem. Int. Ed. Engl. 59, 5788-5796 (2020).

25. Zhu, X. et al. Lead halide perovskites for photocatalytic organic synthesis. Nat. Commun. 10, 2843 (2019)

26. Wang, X. D., Li, W. G., Liao, J. F. \& Kuang, D. B. Recent advances in halide perovskite single-crystal thin films: fabrication methods and optoelectronic applications. Sol. RRL 3, 1800294 (2019).

27. Weinberg, N. L. \& Weinberg, H. R. Electrochemical oxidation of organic compounds. Chem. Rev. 68, 449-523 (1968).

28. Zhang, J. et al. One-pot synthesis of 3-(furan-2-yl)-4-hydroxy-2H-chromen-2 ones using K10 montmorillonite clay as heterogeneous catalyst. Tetrahedron 74, 4712-4720 (2018).

29. Clauson-Kaas, N., Limborg, F. \& Fakstorp, J. The alkoxylation of simple furans and related reactions. Acta Chem. Scand. 2, 109-115 (1948).

30. Tateno, H., Miseki, Y. \& Sayama, K. Photoelectrochemical dimethoxylation of furan via a bromide redox mediator using a $\mathrm{BiVO}_{4} / \mathrm{WO}_{3}$ photoanode. Chem. Commun. 53, 4378-4381 (2017).

31. Rao, H.-S., Li, W.-G., Chen, B. X., Kuang, D.-B. \& Su, C.-Y. In situ growth of $120 \mathrm{~cm}^{2} \mathrm{CH}_{3} \mathrm{NH}_{3} \mathrm{PbBr}_{3}$ perovskite crystal film on FTO glass for narrowbandphotodetectors. Adv. Mater. 29, 1602639 (2017).

32. Rao, H.-S., Chen, B.-X., Wang, X.-D., Kuang, D.-B. \& Su, C.-Y. A micron-scale laminar $\mathrm{MAPbBr}_{3}$ single crystal for an efficient and stable perovskite solar cell. Chem. Commun. 53, 5163-5166 (2017).

33. Saidaminov, M. I. et al. Planar-integrated single-crystalline perovskite photodetectors. Nat. Commun. 6, 8724 (2015).

34. Peng, W. et al. Solution-grown monocrystalline hybrid perovskite films for hole-transporter-free solar cells. Adv. Mater. 28, 3383-3390 (2016).

35. Ni, Z. et al. Resolving spatial and energetic distributions of trap states in metal halide perovskite solar cells. Science 367, 1352-1358 (2020).

36. Fu, Y. et al. Metal halide perovskite nanostructures for optoelectronic applications and the study of physical properties. Nat. Rev. Mater. 4, 169-188 (2019).

37. Yang, Y. et al. Top and bottom surfaces limit carrier lifetime in lead iodide perovskite films. Nat. Energy 2, 16207 (2017).

38. Koushik, D. et al. Chemical analysis of the interface between hybrid organic-inorganic perovskite and atomic layer deposited $\mathrm{Al}_{2} \mathrm{O}_{3}$. ACS Appl. Mater. Interfaces 11, 5526-5535 (2019).

39. Liu, S. C. et al. Investigation of oxygen passivation for high-performance all-inorganic perovskite solar cells. J. Am. Chem. Soc. 141, 18075-18082 (2019).

40. Lu, D. L. et al. Giant light-emission enhancement in lead halide perovskites by surface oxygen passivation. Nano Lett. 18, 6967-6973 (2018).

41. Chi, X. et al. Elucidating surface and bulk emission in 3D hybrid organic-inorganic lead bromide perovskites. Adv. Opt. Mater. 6, 1800470 (2018).

42. Doherty, T. A. S. et al. Performance-limiting nanoscale trap clusters at grain junctions in halide perovskites. Nature 580, 360-366 (2020).

43. $\mathrm{Wu}, \mathrm{B}$. et al. Discerning the surface and Bulk recombination kinetics of organic-inorganic halide perovskite single crystals. Adv. Energy Mater. 6, 1600551 (2016)

44. Yang, Y. et al. Low surface recombination velocity in solution-grown $\mathrm{CH}_{3} \mathrm{NH}_{3} \mathrm{PbBr}_{3}$ perovskite single crystal. Nat. Commun. 6, 7961 (2014).

45. Stern, F. Dispersion of the index of refraction near the absorption edge of semiconductors. Phys. Rev. 133, A1653-A1664 (1964)

46. Tong, J. et al. Carrier lifetimes of $>1 \mu$ s in $\mathrm{Sn}-\mathrm{Pb}$ perovskites enable efficient all-perovskite tandem solar cells. Science 364, 475-479 (2019).

47. Zhang, Z. \& Yates, J. T. Jr. Band bending in semiconductors: chemical and physical consequences at surfaces and interfaces. Chem. Rev. 112, 5520-5551 (2012).

48. Jeong, S. H., Park, Y. J., Kim, B. S. \& Song, H. J. Effects of oxygen content on bioactivity of titanium oxide films fabricated on titanium by electron beam evaporation. J. Nanosci. Nanotechnol. 7, 3815-3818 (2007). 
49. Zhao, Y. et al. Ultrafine $\mathrm{NiO}$ nanosheets stabilized by $\mathrm{TiO}_{2}$ from monolayer NiTi-LDH precursors: an active water oxidation electrocatalyst. J. Am. Chem. Soc. 138, 6517-6524 (2016).

50. Le, F. F., Grätzel, M. \& Sivula, K. Controlling photoactivity in ultrathin hematite films for solar water-splitting. Adv. Funct. Mater. 20, 1099-1107 (2010).

51. Moser, M., Czekaj, I., López, N. \& Pérez-Ramírez, J. The virtue of defects: stable bromine production by catalytic oxidation of hydrogen bromide on titanium oxide. Angew. Chem. Int. Ed. 53, 8628-8633 (2014).

52. Wang, B. et al. Unconventional route to oxygen-vacancy-enabled highly efficient electron extraction and transport in perovskite solar cells. Angew. Chem. Int. Ed. 59, 1611-1618 (2020).

53. $\mathrm{Wu}, \mathrm{T}$. et al. Identifying the origin of $\mathrm{Ti}^{3+}$ activity toward enhanced electrocatalytic $\mathrm{N}_{2}$ reduction over $\mathrm{TiO}_{2}$ nanoparticles modulated by mixedvalent copper. Adv. Mater. 32, 2000299 (2020).

54. Amano, F., Nakata, M., Yamamoto, A. \& Tanaka, T. Effect of $\mathrm{Ti}^{3+}$ ions and conduction band electrons on photocatalytic and photoelectrochemical activity of rutile titania for water oxidation. J. Phys. Chem. C 120, 6467-6474 (2016).

55. Babayigit, A., Ethirajan, A., Muller, M. \& Conings, B. Toxicity of organometal halide perovskite solar cells. Nat. Mater. 15, 247-251 (2016).

56. Ke, W. \& Kanatzidis, M. G. Prospects for low-toxicity lead-free perovskite solar cells. Nat. Commun. 10, 965 (2019)

57. Hutter, J., Iannuzzi, M., Schiffmann, F. \& VandeVondele, J. CP2K: atomistic simulations of condensed matter systems. Wires Comput. Mol. Sci. 4, 15-25 (2014).

58. Perdew, J. P., Burke, K. \& Ernzerhof, M. Generalized gradient approximation made simple. Phys. Rev. Lett. 77, 3865-3868 (1996).

59. Grimme, S. Semiempirical GGA-type density functional constructed with a long-range dispersion correction. J. Comput. Chem. 27, 1787-1799 (2006).

60. Goedecker, S., Teter, M. \& Hutter, J. Separable dual-space Gaussian pseudopotentials. Phys. Rev. B 54, 1703-1710 (1996).

61. Hartwigsen, C., Godecker, S. \& Hutter, J. Relativistic separable dual-space Gaussian pseudopotentials from H to Rn. Phys. Rev. B 58, 3641-3662 (1998).

62. VandeVondele, J. \& Hutter, J. Gaussian basis sets for accurate calculations on molecular systems in gas and condensed phases. J. Chem. Phys. 127, 114105 (2007).

63. VandeVondele, J. et al. QUICKSTEP: fast and accurate density functional calculations using a mixed Gaussian and plane waves approach. Comput. Phys. Commun. 167, 103-128 (2005).

\section{Acknowledgements}

The authors acknowledge the financial support from the National Key R\&D Program of China (2019YFB1503200), the National Natural Science Foundation of China (U2001214,

21802172, 21875288, and 22075333), the GDUPS (2016), the NSF of Guangdong Province
(2019B151520050, 2018A030313009), and the Fundamental Research Funds for the Central Universities. The authors thank to XPS group in surface and structure analysis platform of Instrumental Analysis \& Research Center, Sun Yat-sen University.

\section{Author contributions}

X.D.W. and D.B.K. designed the project. X.D.W., Z.F.W., and W.G.L. prepared the $\mathrm{MAPbBr}_{3}$ perovskite single-crystal thin films and photoelectrodes. X.D.W. performed the photophysical properties characterization, Y.H.H., Z.F.W., and X.D.W. performed the photoelectrochemical studies and 2,5-dimethoxy-2,5-dihydrofuran evolution experiments. X.D.W., J.F.L., Y.F.X., H.Y.C., and D.B.K. wrote the manuscript with input and discussion from all authors. All the authors analysed the results and reviewed the paper

\section{Competing interests}

The authors declare no competing interests.

\section{Additional information}

Supplementary information The online version contains supplementary material available at https://doi.org/10.1038/s41467-021-21487-8.

Correspondence and requests for materials should be addressed to D.-B.K.

Peer review information Nature Communications thanks the anonymous reviewers for their contributions to the peer review of this work.

Reprints and permission information is available at http://www.nature.com/reprints

Publisher's note Springer Nature remains neutral with regard to jurisdictional claims in published maps and institutional affiliations.

(c) (i) Open Access This article is licensed under a Creative Commons Attribution 4.0 International License, which permits use, sharing, adaptation, distribution and reproduction in any medium or format, as long as you give appropriate credit to the original author(s) and the source, provide a link to the Creative Commons license, and indicate if changes were made. The images or other third party material in this article are included in the article's Creative Commons license, unless indicated otherwise in a credit line to the material. If material is not included in the article's Creative Commons license and your intended use is not permitted by statutory regulation or exceeds the permitted use, you will need to obtain permission directly from the copyright holder. To view a copy of this license, visit http://creativecommons.org/ licenses/by/4.0/.

(c) The Author(s) 2021 